\title{
Current research and clinical trials for a vaccine against Chikungunya virus
}

\author{
This article was published in the following Dove Press journal: \\ Vaccine: Development and Therapy \\ 8 August 2013 \\ Number of times this article has been viewed
}

\section{Priyanka Singh' \\ Mala Chhabra' \\ Veena Mittal' \\ Pankaj Sharma' \\ Moshahid A Rizvi \\ Lakhvir Singh Chauhan' \\ Arvind Rai' \\ 'National Centre for Disease Control, Sham Nath Marg, ${ }^{2}$ Department of Biosciences, Jamia Millia Islamia, New Delhi, India}

Correspondence: Mala Chhabra National Centre for Disease Control, 22-Sham Nath Marg, New Delhi I 10054, India Tel +9| II 23909236

Fax +9| II 23922677

Emailmalachhabra@yahoo.co.in
Abstract: Chikungunya infection is a self-limiting Aedes mosquito-borne arboviral disease with variable clinical manifestations, ranging from asymptomatic illness to a very severe and crippling arthralgia. Until recently, Chikungunya was a little known disease that re-emerged in 2005-2006, leading to major outbreaks on the Indian Ocean Islands and in South East Asia, and eventually extending its range to temperate regions. It drew global attention due to its explosive onset, extensive geographic distribution, and high morbidity. Since re-emergence, an estimated one million symptomatic cases with $0.1 \%$ fatality per year have been reported globally. A lack of herd immunity, vector control, and globalization and trade are clearly a problem in the spread of this disease. The Chikungunya virus (CHIKV) has also acquired biologically important mutations during its evolution, increasing its geographic reach. This disease has resulted in a loss of productivity in affected communities. The absence of a vaccine or an effective antiviral therapy makes dealing with this disease challenging for those involved in public health. There is an emergent need for an effective vaccine against CHIKV infection. The candidates that have been tested include attenuated living, nonliving and genetically engineered vaccines. Several of these vaccine candidates are in preclinical and clinical trials. This review outlines the current knowledge about chikungunya infection and vaccine development.

Keywords: Chikungunya, outbreaks, epidemics, genotypes, vaccines, therapy

\section{Introduction}

Chikungunya (CHIK) infection is an arboviral disease caused by Chikungunya virus (CHIKV) that is transmitted by the bite of infected Aedes mosquitoes. It was an unknown disease in most of the world until a major epidemic in 2006 on the Indian Ocean Islands and in South East Asia, including India. After a hiatus of 32 years, resurgence of CHIK fever drew global attention due to its explosive onset, extensive and expanding geographic distribution, high morbidity, and varied clinical manifestations. ${ }^{1-3}$

Following an outbreak in a Swahili village in Tanzania, a new viral disease was described in 1952. The word Chikungunya is derived from the Makonde language, from the root verb "kungunyala", which means to "dry up" or "become contorted". ${ }^{4,5}$ In the Democratic Republic of Congo, this disease has been called "buka-buka", meaning "broken-broken", reflecting the incapacitating arthralgia that is a common acute manifestation of CHIK infection. Literally, the word "Chikungunya" translates to "that which bends up", referring to the stooped posture developed due to the rheumatologic manifestation of the disease. ${ }^{6}$ 
CHIKV infections have been documented in several parts of tropical Africa and South East Asia since the 1960s. Since 2005, the Indian Ocean Islands and South East Asia are facing an unparalleled outbreak of CHIKV. ${ }^{7}$ India experienced a re-emergence of CHIKV after a quiescence of nearly three decades. The epidemic affected 1.3 million people in 2006-2007. ${ }^{8}$ The presence of CHIKV in European countries, such as Italy, France and Spain, was reported in 2008. ${ }^{9-12}$ Globally, an estimated one million symptomatic cases, with a $0.1 \%$ fatality rate per year, have been reported. CHIKV has been identified in nearly 40 countries around the world. In 2008 it was declared to be a category $\mathrm{C}$ priority pathogen by the US National Institutes of Health. ${ }^{13}$

CHIK infection is considered an important public health problem due to the morbidity and disability caused by chronic arthralgia. The social and economic burden caused by CHIK fever is tremendous. ${ }^{14}$ Hence, there is an urgent need for an effective vaccine or antiviral therapy against CHIKV infection.

\section{Structure and genome organization}

The CHIKV is an arbovirus that belongs to the family Togaviridae, genus alphavirus, and species Chikungunya virus. The virus particle is small (60-70 nm diameter) and spherical, with a capsid and a phospholipid envelope that contains hemagglutinin protein spikes. It is sensitive to desiccation and temperature above $58^{\circ} \mathrm{C}$. CHIKV has a linear, positivesense, single-stranded RNA genome of approximately 11,805 nucleotides. ${ }^{15-19}$ The $5^{\prime}$ end of the genome encodes the nonstructural proteins and makes up two thirds of the viral genome. These are required for viral replication. The structural genes are the remaining one third of the viral genome and are at the $3^{\prime}$ end. The genome of CHIKV is organized as follows: 5' cap-nsP1-nsP2-nsP3-nsP4-(junction region)C-E3-E2-6K-E1-poly(A). The CHIKV genome resembles a eukaryotic mRNA in that it possesses a $5^{\prime}$ cap structure and a $3^{\prime}$ poly (A) tail. Coding sequences consist of two large open reading frames of 7,422 nucleotides and 3,732 nucleotides, encoding the nonstructural polyprotein (2474 amino acids) and the structural polyprotein (1244 amino acids), respectively. The nonstructural polyprotein is a precursor of proteins nsP1 (535 amino acids), nsP2 (798 amino acids), nsP3 (530 amino acids), and nsP4 (611 amino acids). The structural polyprotein is a precursor of proteins $C$ (261 amino acids), E3 (64 amino acids), E2 (423 amino acids), and E1 (435 amino acids). ${ }^{20}$

In the alphavirus genus, about 30 species of arthropod-borne viruses are antigenically classified into seven complexes.
These species are widely distributed throughout the world, with the exception of Antarctica. CHIKV has been grouped under Semliki Forest Virus antigenic complex and is most closely related to the O'nyong-nyong virus among the associated alphaviruses, although both viruses remain distinct from each other. ${ }^{21-23}$

\section{Vectors and disease transmission}

CHIKV is transmitted by the mosquitoes Aedes aegypti and Aedes albopictus in Asia and the Indian Ocean region. ${ }^{24}$ In Africa, mostly Aedes species transmit the virus, but Culex annulirostris, Mansonia uniformis, and Anopheles mosquitoes have also been implicated occasionally. ${ }^{25-27}$ Aedes is a diurnal vector, with peak activity at the end of the day. A. aegypti is a day-biter. It feeds and rests indoors, while $A$. albopictus is more active outdoors. ${ }^{28}$ Only the bite of the female mosquito is considered to be infective, because a blood meal is required for the formation of eggs. ${ }^{29}$ The same vector can, at times, transmit several different arboviruses. Mixed epidemics of CHIK fever along with dengue fever and yellow fever have been documented. ${ }^{30-33}$

In India, A. aegypti is a dominant vector for CHIKV transmission. It breeds mainly in stored fresh water in urban and semiurban environments. ${ }^{34}$ The mosquito's eggs are very resistant and can remain viable throughout the dry season, giving rise to larvae and adults in the following rainy season. ${ }^{35}$ A. albopictus has a remarkable capacity to adapt to human beings and urbanization, and hence it has superseded A. aegypti as the vector in many places. ${ }^{36}$

The transmission cycle of CHIKV differs in Asia and Africa. CHIKV is maintained in a mosquito-human-mosquito cycle in Asia. In Africa, it is maintained in a sylvatic cycle involving wild primates and forest-dwelling Aedes mosquitoes. ${ }^{37}$ Monkeys, rodents, birds, and possibly other wild animals may also serve as reservoirs of the virus. ${ }^{38}$ Isolates of CHIKV obtained from zoophilic mosquitoes suggest the role of cattle in CHIKV transmission, although the role of ruminants may be negligible. ${ }^{39}$

\section{Geographic distribution}

CHIKV is primarily distributed in the tropical regions, but has expanded its range into the temperate regions with its re-emergence in 2005. Due to a wide range of vector species and reservoirs, the disease is known to be endemic mainly in rural Africa. ${ }^{33,37}$ However, epidemics/outbreaks due to three genotypes of CHIKV have been reported in different geographic regions. 
The epidemic form of CHIKV is present in Asia. It is mainly transmitted by two vectors (A. aegypti and A. albopictus) to populations having less herd immunity and hence causes massive epidemics with high attack rates. The epidemic peaks and then declines gradually as the majority of the population develops immunity due to clinical or subclinical infection. ${ }^{40}$

Human infections caused by CHIKV were reported for the first time in East Africa about six decades ago in 1952-1953 during an epidemic of fever that developed along the border between Tanzania and Mozambique, and was reported as a "dengue-like fever". ${ }^{41,42}$ The first report was published in 1955, and since then isolated cases or outbreaks have been reported in Asia and several countries in Africa (Benin, Burundi, Cameroon, Central African Republic, Kenya, Uganda, Malawi, Senegal, Congo, Nigeria, Sudan, Guinea, South Africa, Tanzania, Zimbabwe, Namibia, Comoros, Mayotte, Ghana, Burkina Faso, Mozambique, and Gabon). Most of the CHIKV cases in Asia were reported in India, Sri Lanka, Myanmar, Thailand, Vietnam, Taiwan, Singapore, Cambodia, Pakistan, Laos, Philippines, Malaysia, Indonesia, and East Timor. ${ }^{43}$

In 1962, the largest CHIKV outbreaks were reported in India and Sri Lanka, which infected more than 100,000 persons and caused 200 deaths. Several million people suffered in the CHIKV outbreaks during the first half of this decade. . $^{4,45}$

India had its first documented CHIKV outbreak during 1963-1964 in Calcutta, followed by an outbreak in the southern parts of India (Madras, Pondicherry, and Vellore) in 1965 , affecting 0.3 million people. ${ }^{46-48}$ The activity of CHIKV circulation seemed to decline during 1965-1972, with a few sporadic cases reported from South India. After a quiescence of about a decade, a CHIKV outbreak in India was reported in Barsi, Maharashtra, in 1973. After 1975, circulation of CHIKV nearly disappeared from India and no cases were reported until the end of 2005. . $2,40,49-51^{2}$

CHIKV re-emerged in 2005 on the Indian Ocean Islands, where cases were reported from Seychelles, Mayotte, Madagascar, Mauritius, and Reunion. ${ }^{52}$ In particular, between February 2005 and March 2006, CHIKV infection covered an enormous population of the French Island of Reunion, located in the Indian Ocean off the east coast of Madagascar. During this epidemic, it is estimated that the deaths of 200 people were associated with CHIKV infection. ${ }^{53-56} \mathrm{After}$ this, CHIKV moved towards the Indian subcontinent and produced a massive outbreak in India, affecting 213 districts in 15 states and union territories in 2005-2006. ${ }^{8}$ Almost all parts of South East
Asia, including Sri Lanka, Indonesia, Malaysia, Thailand, and Singapore, reported cases of CHIKV infection. ${ }^{57-60}$ Isolated or small clusters of potentially imported cases have also been found in different parts of the world, ie, the European and North American countries (Canada and the US). Imported cases have also been reported in Germany, Switzerland, Italy, Norway, Australia, and French Guyana, and among US Peace Corps volunteers in the Philippines. ${ }^{61-63}$ A small outbreak of CHIKV was reported from the temperate areas in the Emilia Romagna region in Italy during 2007. The People's Republic of China experienced its first CHIKV outbreak in $2010 .{ }^{64}$ CHIKV has been expanding its geographic horizons from Africa to Asia and now into the western hemisphere.

\section{Clinical features}

Clinical manifestations of CHIKV infection range from an asymptomatic illness to debilitating disease. Children and elderly adults are at highest risk for severe manifestation of the disease ${ }^{65}$ The documented classical triad of CHIKV infection includes fever, arthralgia, and a rash that may or may not be accompanied by other indicators of the disease. CHIKV illness normally begins with a sudden onset of fever reaching as high as $40^{\circ} \mathrm{C}$ that may last up to 10 days. ${ }^{66-68}$ The fever almost always precedes the rash and joint pain, and has occasionally been reported as biphasic with a recurrence noted on days 4-5 of illness, also described as "saddle-back fever". ${ }^{69}$ The nonpruritic rash is normally maculopapular and erythematous in character and is distributed primarily on the face, limbs, and trunk of the body. Rash is usually visible $2-5$ days post infection and may last up to 10 days. $^{70,71}$

The most significant manifestation of CHIKV illness is severe pain in the joints, which is the hallmark feature of this disease. The arthralgia is manifested in the ankles, toes, fingers, elbows, wrists, and knees, with incapacitating pain that lasts for weeks or months. Nearly all infections resolve completely within weeks or months, but there have been documented cases of CHIKV-induced arthralgia persisting for several years, with approximately $12 \%$ of patients with CHIKV disease developing chronic joint problems. ${ }^{67,72}$ One case has been reported of probable CHIK arthritis progressing to joint destruction before ultimately subsiding after 15 years, causing a sequelae of destroyed metatarsal heads and late osteoarthritic changes in the ankles. ${ }^{73}$ Other clinical features reported with CHIKV infection include headache, retro-orbital pain, photophobia, lumbar back pain, chills, weakness, nausea, vomiting, and myalgia. ${ }^{67,74}$ Conjunctivitis, pharyngitis, and lymphadenopathy may also be observed. Because of their similar clinical presentation, 
differential diagnosis of CHIK infection from dengue fever, O'nyong nyong virus, Sindbis virus, Ross river virus, malaria, and leptospirosis may be difficult. Definite diagnosis of CHIK infection can only be confirmed by laboratory tests. ${ }^{51,75-78}$

\section{Diagnosis}

A number of methods are used for diagnosing CHIKV infection. The type of test performed typically depends on the timing and volume of samples available. ${ }^{79}$ Virus isolation and nucleic acid detection are possible from serum specimens collected during the first 7 days of illness. IgM antibodies are detectable after about a week of illness and these persist for several weeks. The IgG antibodies are detected in convalescent samples and these persist for years. ${ }^{75}$

CHIKV can be readily isolated by inoculation of mosquitoes, mosquito cell cultures, mammalian cell culture, or mice. Virus culture is the gold standard for the diagnosis but is seldom performed because it is technically demanding. Serologic methods are simpler and are a mainstay for diagnosis. These are based on inhibition of hemagglutination, complement binding, immunofluorescence, and enzymelinked immunosorbent assay. They are relatively inexpensive, quick, and simple to perform. Molecular methods can be used for rapid detection of minute quantities of CHIK material in the patient's serum. Reverse transcriptase polymerase chain reaction is useful for detection of CHIK infection early in the disease when antibodies are not detected and allows for identification of the circulating genotype..$^{80,81}$

Reverse transcriptase loop-mediated isothermal amplification assay has also been used for diagnosis of CHIKV. This assay is a new approach to nucleic acid amplification. It is based on the strand-displacement reaction and utilizes a stem-loop structure to amplify the target with a high degree of specificity and selectivity. It is a rapid detection method under isothermal conditions, thereby obviating the need for use of a thermal cycler, making possible its use during disease surveillance. ${ }^{82}$

Multiplex polymerase chain reaction can be used for differential diagnosis, which is usually difficult when based solely on the clinical features. Duplex reverse transcriptase polymerase chain reaction was successfully used for diagnosing coinfection during an arboviral outbreak of dengue virus and CHIKV in the post monsoon season of 2010 in Delhi, India. ${ }^{30}$

Biological markers have been identified that indicate the severity of the disease. Increased levels of interleukin (IL)-6 and IL-1 $\beta$ and decreased levels of a chemokine known as RANTES are associated with an increase in severity of the disease. ${ }^{83}$ Another study revealed that the cytokine type 1 interferon plays an important role in progression of CHIKV infection. ${ }^{84}$ Chronic arthralgia may also be associated with high levels of proinflammatory cytokines like IL-6, IL-8, and granulocyte-macrophage colony stimulating factor. ${ }^{85}$

\section{Phylogenesis}

CHIKV isolates from various geographic areas are broadly grouped into three genotypes, ie, Asian, West African, and East Central South African (ECSA). ${ }^{86}$ Genomic variations in CHIKV are associated with geographic origin. The evolutionary rate has been studied using E1 or full genome sequences. ${ }^{53,86,87}$ Genetic analyses suggest that the CHIKV originated in tropical Africa and was later introduced into Asia. ${ }^{86}$ The Asian genotype has a high degree of genetic homogeneity, while a strong geographic pattern underlines the great genetic diversity occurring within the ECSA cluster. ${ }^{53,86,87} \mathrm{CHIKV}$ isolates from the Indian Ocean region since the year 2000 show limited sequence variation and are closely related to the sequence of an ECSA strain isolated 50 years earlier in Tanzania. ${ }^{34,53}$ In the later phase of outbreak in this area, a marked mutational change, ie, replacement of alanine by valine at position 226 in the E1 gene (A226V), appeared in CHIKV strains. Almost 90\% of the latter strains in La Reunion, Mayotte, and Madagascar have this mutation in addition to other known mutations like M269V and D284E. ${ }^{88,89}$ The A226V mutation reduces the cholesterol dependence of the virus to infect mosquito hosts. This mutation is postulated to have facilitated replication and transmission of the virus by A. albopictus. This adaptation of the virus to ecologic perturbation appears to be a unique example of the evolutionary convergence occurring in nature..$^{53,88}$

In India, circulation of the ECSA genotype has been reported since 2006, replacing the earlier Asian genotype. Initially the presence of CHIKV was reported in the southern part of India. After that, northward movement of the virus with the same genotype was reported.${ }^{90} \mathrm{~A} 226 \mathrm{~V}$ mutation was absent in all 2006 isolates, while it was primarily observed in isolates of the southern state of Kerala in 2007. After that, other Indian states also reported this mutation. ${ }^{91-96}$ Another molecular signature evolved from India, where replacement of lysine by glutamic acid at position 211 in the E1 gene of CHIKV was noticed. ${ }^{97,98} \mathrm{E} 1-211 \mathrm{E}$ is highly conserved in Asian genotypes of the virus. The mutation K211E also occurred in an Indian isolate imported to France from the state of Rajasthan in India. ${ }^{11} \mathrm{~A}$. aegypti is a common vector for circulation of this genotype. In India, two clades of 
the ECSA genotype are in circulation corresponding to the presence of vectors $A$. albopictus and $A$. aegypti. ${ }^{97}$

In Southeast Asia, Sri Lanka reported both the K211 N and A226V mutations in the isolates of the year $2008 .{ }^{60}$ Thailand had the $\mathrm{A} 226 \mathrm{~V}$ mutation which gave rise to a massive outbreak in 2008-2009. Initially in Singapore, in the absence of the A226V mutation, morbidity was low and the outbreak was rapidly controlled. However, the A226 mutation appeared during 2008 in Singapore CHIKV isolates. ${ }^{99,100}$ Acquisition and fixation of mutations may be a common pathway for the explosion of CHIK in epidemic areas in a parallel interplay with the mosquito vector dynamics.

\section{Treatment}

Currently, no effective antiviral treatment is available against CHIKV infection. The infection is usually self-limiting and resolves with time. Treatment is purely symptomatic and includes bed rest during the febrile period, an extra fluid diet, and antipyretics and analgesics like naproxen or paracetamol. ${ }^{35,65}$ Salicylates and other nonsteroidal antiinflammatory drugs should be avoided because they may cause bleeding manifestations, nausea, vomiting, and gastritis. ${ }^{75,101}$ Post illness arthritis may need prolonged treatment with anti-inflammatory drugs and graduated physiotherapy. ${ }^{29}$ Chloroquine, a drug useful for prophylaxis and treatment of malaria, was reported to be helpful for treating chronic CHIK arthritis. ${ }^{102}$ However, in a trial conducted during an outbreak on the French Reunion Island, where one group (27 patients) received five days of chloroquine and another group (27 patients) received placebo, no significant difference was observed between the two groups with respect to duration of febrile arthralgia or the degree of viremia. On day 200, patients who were taking chloroquine complained of arthralgia more frequently than those taking the placebo. Thus, the study concluded that there was no justification for the use of chloroquine in acute CHIKV infection. ${ }^{103}$ However, anti-CHIKV activity of chloroquine was determined in virus yield from Vero cells treated with the drug as compared with untreated infected control cells. The viral titer was observed to be reduced by $99 \%$ using nearly $20 \mu \mathrm{M}$ chloroquine. ${ }^{104}$ Hence, possible use of chloroquine for treatment of arthralgia caused by CHIKV needs further investigation. Ribavirin showed antiviral properties against CHIKV infection. Doses of $200 \mathrm{mg}$ twice a day administered to patients who continued to have crippling lower limb pains and arthritis for at least 2 weeks after febrile episodes led to faster resolution of joint and soft tissue manifestations. ${ }^{105}$ The combination of interferon- $\alpha 2 b$ and ribavirin has been reported to have a synergistic antiviral effect against CHIKV infection in vitro. ${ }^{106}$

\section{Prevention and control}

Currently there is no vaccine or a specific medication available to prevent CHIK infection. Vector control remains the mainstay in cutting down CHIKV transmission. Elimination of breeding sites and source reduction are the most effective methods for the control of mosquitoes. This can be achieved by eliminating or cleaning up small waterholding receptacles, eg, cisterns, barrels, old tyres, tin cans, buckets, drums, and bottles. To eliminate mosquito larvae in ornamental water tanks and gardens, either larvicides or larvivorous fish (gambusia or guppy) can be used.

Insecticides can be used to kill both larvae and mosquitoes. For knockdown of adult mosquitoes, well planned fogging operations are recommended with $2 \%$ pyrethrum space spray in high-risk areas where clusters of cases have been reported. ${ }^{51}$ Control of the mosquito population is difficult to achieve and very difficult to sustain. It has been reported that large-scale use of dichlorodiphenyltrichloroethane has been effective only against $A$. aegypti and not $A$. albopictus. ${ }^{107}$ Resistance patterns of $A$. aegypti and A. albopictus vary for different insecticides. ${ }^{108}$

Individuals need to protect against mosquito bites. This can be done by using mosquito repellent, limiting skin exposure by wearing long sleeves, leggings, or pants, and by use of mosquito nets over beds, especially during the daylight hours. Creating genetically modified mosquitoes that are unable to transmit the virus is a new promising method under investigation. ${ }^{109}$

Active surveillance of an area is an important component for prevention of the disease. Epidemiologic and entomologic surveys should be done. The goal of surveillance should be to identify areas for initiating control measures and subsequently assessing the impact of these measures. Information, education, and communication activities are essential for community sensitization and participation. In endemic areas, people should be encouraged to use personal protection and vector control measures. Education should be provided to people on various aspects of the disease through special campaigns with the involvement of print and mass media. ${ }^{51}$

\section{Vaccine development}

Currently, there are no commercial vaccines available for preventing CHIKV infection. Due to a significant infection rate for CHIKV during outbreaks, along with an extensive and expanding geographic distribution, a CHIKV vaccine 
is highly desirable. Constructing a successful vaccine for CHIKV has been challenging. A potential vaccine must provide a balance between the level of immunogenicity it evokes and attenuation of CHIK pathogenicity. Vaccineinduced immunogenicity should be such that the level of neutralizing antibodies produced is sufficient to provide complete protection against CHIKV, but the vaccine should also be sufficiently attenuated so as not to cause unacceptable reactogenicity. The adaptive immune response should be able to protect the individual against reinfection belonging to any serotype/genotype. It is believed that CHIKV consists of three genotypes with no distinct serotype. It is a widespread belief that the herd immunity generated by one epidemic confers lasting protection against infection by other genotypes and genotypic variants. ${ }^{97,110}$ Hence, vaccines made from seed virus of human strains should have efficacy for all three genotypes.

Vaccine candidates should be able to induce high levels of neutralizing antibodies in response to immunization, ideally with only one inoculation. In addition, successful vaccine candidates must keep the virus titers in a vaccinated human low to prevent a biting mosquito from becoming infected and allowing further replication of the virus. Since the most significant infection rates are in developing countries, an ideal vaccine should also be economical and affordable. The history of vaccine development for CHIKV is minimal and none of the efforts have produced complete successful results yet. A number of vaccine candidates such as whole virus inactivation, live attenuated virus, and genetically engineered vaccines are in different stages of clinical trials (Table 1).

The initial work on the CHIKV vaccine for human beings began in the early 1970s. The first vaccine trial involved using a whole virus grown in green monkey kidney tissue culture cells and had been inactivated by fixation in formalin. Experimental formalin-killed vaccines were prepared with four CHIKV isolates (human isolates from Thailand, strains 6348, 6461, 15561, and 23337) in green monkey kidney cells at passage levels 5 and 10 . CHIK isolate 15561 was arbitrarily chosen as a "vaccine seed virus" because statistical analysis of mouse potency results from these vaccine lots revealed no significant difference between the potency values obtained for each isolate. Potency tests were conducted in mice and monkeys and were followed up with a human volunteer study. In a Phase I clinical trial in human volunteers, CHIK 15561 elicited an excellent immune response without showing any adverse effects. ${ }^{11}$ Eckels et al inactivated CHIKV strains (African 168, Asian BAH-306, Indian C-266) by using the Tween ether extraction method. This vaccine candidate was also shown to be immunogenic and provided protection against three heterologous strains of CHIKV. ${ }^{12}$

Table I Current Chikungunya vaccine strategies

\begin{tabular}{|c|c|c|c|}
\hline Approach & Method & Status & Reference \\
\hline \multirow[t]{3}{*}{ Inactivated vaccine } & Formalin-inactivated CHIKV Thailand strain I556I grown on GMK cells & Phase I & Harrison et al"II \\
\hline & $\begin{array}{l}\text { Tween ether-inactivated CHIKV strains (African 168, Asian BAH-306, } \\
\text { and Indian C-266) grown on GMK cells }\end{array}$ & Preclinical & Eckels et al ${ }^{112}$ \\
\hline & $\begin{array}{l}\text { Formalin-inactivated } 2006 \text { Indian strain grown on Vero cells } \\
\text { adjuvanted by Alhydrogel }{ }^{\circledR}\end{array}$ & Preclinical & Tiwari et al $\left.\right|^{113}$ \\
\hline \multirow[t]{2}{*}{$\begin{array}{l}\text { Live-attenuated } \\
\text { vaccine }\end{array}$} & $\begin{array}{l}\text { Attenuated CHIK I8I/clone } 25 \text { developed by serial passage of CHIKV } \\
\text { Thailand strain I556I in MRC-5 cells }\end{array}$ & Preclinical & Levitt et $\mathrm{al}^{1 / 4}$ \\
\hline & $\begin{array}{l}\text { Live, attenuated TSI-GSD-2I8, CHIKV vaccine-infected with an attenuated } \\
\text { strain, CHIK } 181 / \text { clone } 25\end{array}$ & $\begin{array}{l}\text { Completed } \\
\text { Phase II }\end{array}$ & Edelman et al ${ }^{116}$ \\
\hline \multirow[t]{6}{*}{$\begin{array}{l}\text { Genetically } \\
\text { engineered vaccines }\end{array}$} & $\begin{array}{l}\text { Chimeric vaccine: Using three alphavirus vaccine backbones; VEEV, EEEV, SINV } \\
\text { and replacing the specific structural protein coding sequence with La Reunion strain }\end{array}$ & Preclinical & Wang et $\mathrm{al}^{117}$ \\
\hline & $\begin{array}{l}\text { CHIKV genes inserted into nonreplicating adenovirus vectors produce recombinant } \\
\text { expressing structural sequence from Asian and ECSA genotype isolates }\end{array}$ & Preclinical & Wang et al ${ }^{120}$ \\
\hline & $\begin{array}{l}\text { CHIK-IRES: replacement of structural proteins for altering levels and host } \\
\text { specific mechanism, CHIKV/IRES by EMCV/IRES }\end{array}$ & Preclinical & Plante et al ${ }^{\mid 21}$ \\
\hline & DNA vaccine: encoding C, EI, E2 genes of CHIKV by using three individual plasmids & Preclinical & Muthumani et al $\left.\right|^{122}$ \\
\hline & DNA vaccine encoding envelope glycoprotein by using single plasmid & Preclinical & Mallilankaraman et al ${ }^{123}$ \\
\hline & $\begin{array}{l}\text { VLP vaccine: selective expression of viral structural proteins gives } \\
\text { to VLPs from } 37997 \text { and LR2006 OPY-I strains }\end{array}$ & Preclinical & Akahata et al ${ }^{124}$ \\
\hline Therapy & $\begin{array}{l}\text { Passive immunization: purified immunoglobulin extracted from CHIKV patients } \\
\text { siRNA: designing of siRNA against conserved region of nsP3 and EI gene }\end{array}$ & $\begin{array}{l}\text { Preclinical } \\
\text { In vitro }\end{array}$ & $\begin{array}{l}\text { Couderc et al }\left.\right|^{126} \\
\text { Dash et al }{ }^{127}\end{array}$ \\
\hline
\end{tabular}

Abbreviations: CHIK, Chikungunya; CHIKV, Chikungunya virus; GMK, green monkey kidney; VLP, virus-like particles; siRNA, small interfering RNA; IRES, internal ribosome entry sequence; EMCV, Encephalomyocarditis virus; VEEV, Venezuelan equine encephalitis virus; EEEV, Eastern equine encephalitis virus; SINV, Sindbis virus. 
Subsequently, inactivated vaccine with adjuvant was prepared and tested in mice. The virus strain related to the ECSA genotype from the 2006 Indian outbreak was adapted in Vero cells, inactivated by formalin and adjuvanted by aluminum hydroxide. The mice were immunized with this Alhydrogel ${ }^{\circledR}$ (InvivoGen, San Diego, CA, USA) gel formulation of inactivated virus preparation and the assessment of both humoral and cellular immune responses included measurement of antibodies by enzyme-linked immunosorbent assay, plaque reduction neutralization test, microcytotoxicity assay, and evaluation of the cytokine profile. ${ }^{113}$

Live attenuated vaccines tend to mimic the natural infection by inducing humoral and cellular responses which may confer lifelong immunity, often giving the advantage of requiring only one or two doses of vaccinate shot. The weakened form of a live virus allows production of antibodies to both the structural and nonstructural proteins of the virus. For CHIVK, attenuation was first achieved by Levitt et al in 1986 by passaging the virus (CHIK strain 15561, Thailand) in MRC-5 culture cells and selected CHIK 181/Clone 25 as the "vaccine seed". The selection of a vaccine seed virus was based on the induction of high titers of neutralizing antibody and protection against challenge. The vaccine elicited neutralizing antibodies and protected mice and rhesus monkeys against CHIKV infection. ${ }^{114}$ The transmission potential of live attenuated virus vaccine was also evaluated in mosquitoes by oral and intrathoracic inoculation of the virus. Assessment of vaccine was conducted on A. aegypti and A. albopictus, the most common vectors for transmission of the virus. Although the vaccine was able to replicate in both species and could be transmitted by mosquitoes that received the virus via intrathoracic inoculation, there was no evidence of reversion to virulence. ${ }^{115}$ However, viral attenuation by serial passage in cell culture has the disadvantage that it may result in unpredictable genetic changes.

A very promising live vaccine, TSI-GSD-218, was developed by United States Army Medical Research Institute of Infectious Diseases in 2000 using an attenuated strain, CHIK 181/Clone 25. In Phase I clinical trials, the vaccine was found to be safe and immunogenic. Phase II human trials conducted in 59 healthy volunteers produced very satisfactory seroconversion rates ( $98 \%$ on day 28 ) and neutralizing antibody titers, persisting in $85 \%$ of cases at one year. Arthralgia occurred in $8 \%$ of the 59 volunteers. ${ }^{116}$ However, the risk of production of chronic rheumatism raised questions on the use of live attenuated virus vaccine.
Unfortunately, this vaccine trial was stopped due to limited resources and lack of commercial potential; other infectious disease research efforts were prioritized to counter the potential threat of use of biological agents by terrorists. ${ }^{75}$ After the resurgence of CHIKV in 2005-2006, efforts were initiated to renew this vaccine. A Material Transfer Agreement was signed on September 6th 2006 by the United States Army Medical Research Institute of Infectious Diseases and the French National Institute of Health and Medical Research focusing on the transfer of records of previous clinical studies and seed stock from which the vaccine was made for further studies including additional clinical trials in the affected areas. A Phase III trial of the US army candidate vaccine is underway (US Embassy in France, press release, September 14, 2006).

A recombinant chimeric vaccine was constructed using the "backbone" of a related alphavirus and replacing the structural genes with corresponding genes from CHIKV. ${ }^{17}$ The backbone contains the capsid and nonstructural proteins and $5^{\prime}$ and $3^{\prime}$ UTRs. The objective is to retain the attenuation properties from the backbone viral vaccine, and incorporate CHIK antigenicity. A genetic recombinant chimeric vaccine candidate was developed in 2008 against CHIKV. Three different versions were made using three alphavirus backbones, ie, Venezuelan equine encephalitis virus (VEEV) attenuated vaccine strain TC-83, Eastern equine encephalitis virus (EEEV) attenuated vaccine strain BeAr436087, and Sindbis virus (SINV) attenuated vaccine strain AR339. In these strains VEEV, EEEV and SINV specific structural polyprotein coding sequence was replaced with the corresponding CHIKV La Reunion strain genes. The nsPs and cis-acting RNA elements (that include $5^{\prime}$ and $3^{\prime}$ termini and subgenomic promoters) remained backbone-specific. ${ }^{117}$

These three CHIKV vaccine strains were tested in mouse models of different ages. The chimeras were found to induce robust humoral immunity and did not produce detectable reactogenicity. None of the adult or neonatal vaccinated mice when challenged with CHIKV exhibited any sign of neurologic disease, febrile response, or growth delays as indicated by continued weight gain. While comparing chimeras and the live attenuated US Army vaccine, the US Army vaccine resulted in higher levels of viremia and replication of virus strain in the joints of neonatal mice. ${ }^{117}$ Chimera vaccine did not produce any such side effects. Sindbis virus chimeras yielded low neutralizing antibody titers in the comparison of Venezuelan equine encephalitis virus and Eastern equine encephalitis virus. ${ }^{117}$ The traditional attenuation approach depends upon cell culture passages, which results in attenuation due to a few point mutations in the viral genome, while 
genetic strategies such as chimeras provide more stable and known attenuations. ${ }^{118}$ In addition to the risk of reactogenicity, attenuation based on a small numbers of point mutations can also result in residual alphavirus infectivity in mosquito vectors. Using such a vaccine in a nonendemic location could support a local transmission cycle. ${ }^{119}$

In 2011, Wang et al used a recombinant vaccine comprised of nonreplicating complex adenovirus vector encoding the structural polyprotein of CHIKV. This vaccine consistently induced high titers of anti-CHIKV antibodies in mice that neutralized both an old Asian isolate and a Reunion Island isolate from recent epidemics belonging to the Asian and ECSA genotypes, respectively. ${ }^{120}$

The vaccine based on a rational attenuation mechanism, which prevents infection to mosquito vectors, was designed by Plante et al. ${ }^{121}$ The construct contains an Encephalomyocarditis virus internal ribosome entry sequence between the CHIKV nonstructural and structural protein genes to attenuate the virus. Attenuation is also achieved by mutations that inactivate the ability of the virus to produce subgenomic RNA for its structural genes, and replace the nonfunctional subgenomic promoter with an internal ribosome entry sequence element to drive the production of structural proteins. This CHIK vaccine showed genetic stability after subsequent passages in Vero cell culture. The CHIK-internal ribosome entry sequence vaccine trials have been conducted in multiple mouse models. This vaccine has shown to induce high levels of neutralizing antibodies against CHIKV and protect mice from CHIKV challenge. ${ }^{121}$

The latest approach in CHIK vaccine design has been the DNA vaccine strategy. This vaccine candidate was constructed on the basis of consensus sequences of structural proteins, ie, C, E1, and E2 from 21 isolates collected from 1952 to 2006. Several modifications were used to improve vaccine efficacy, such as codon and RNA optimization, addition of a Kozak sequence, and substitution of signal peptide by an immunoglobin E leader sequence. Preclinical studies testing each plasmid DNA vaccine candidate were conducted in mouse models. Mice showed significant levels of anti-E1specific, anti-E2-specific, or anti-C-specific IgG antibodies and interferon- $\gamma$ production, suggesting a strong humoralmediated as well as cell-mediated immune response. ${ }^{122}$

In another experiment, a single plasmid was used for a DNA vaccine candidate (instead of three individual plasmids) that encoded the CHIKV envelope glycoprotein (E3, E2, E1). This vaccine provided a more enhanced immune response than the CHIKV structural proteins individually. In the rodent model, the vaccine was able to protect against
CHIKV infection. Induction of hemagglutination inhibition antibodies, virus neutralizing antibodies, and interferon- $\gamma$ was observed in Rhesus macaques. ${ }^{123}$

A new formulation using noninfectious virus-like particles in vitro was explored against CHIKV infection by Akahata et al in $2010 .{ }^{124}$ The virus-like particle vaccines have already been approved by the US Food and Drug Administration for hepatitis $B$ virus and human papillomavirus. The designed CHIK vaccine contains noninfectious virus-like particles coated with the same protein that enables CHIKV to pass through cell walls. The vaccine looks like CHIKV to the immune system, which in turn produces antibodies against it. The vaccine particles do not contain the proteins that CHIKV uses for replication and hence the virus-like particle is safe. Virus-like particles were generated by expressing structural proteins (C-E3-E2-6 K-E1) from an old West African (strain 37997) lineage of CHIKV in 293T human kidney cells. Immunization of monkeys with these virus-like particles elicited neutralizing antibodies against envelope proteins from different CHIKV strains (homologous strains 37997 and a heterologous strain from the recent ECSA genotype, LR2006 OPY-1). These virus-like particle antibodies when transferred to mice protected the mice against lethal CHIKV challenge. ${ }^{124}$ The ongoing Phase I trial is sponsored by the National Institute of Allergy and Infectious Disease. ${ }^{125}$

Passive immunotherapy may be a potential treatment for CHIKV infection as immunotherapy using purified immunoglobulin extracted from convalescent CHIKV patients, has demonstrated effective neutralizing action in vitro and in vivo against CHIKV. ${ }^{126}$

Genetically engineered small interfering RNA is a promising new antiviral strategy. This technique is already successful in partial to complete inhibition of viral replication in several human and animal viruses, like Poliovirus, Cytomegalovirus, Human respiratory syncytial virus, influenza A virus, West Nile virus, and Human immunodeficiency virus. In this approach, two small interfering RNAs against the conserved regions of nsP3 and E1 genes of CHIKV were designed and levels of both the infectious virus and its genome were assessed. The usefulness of small interfering RNA-mediated in vitro replication of CHIKV was demonstrated and offers a potential new therapeutic approach. ${ }^{127}$ Additional studies are required to determine the effect of small interfering RNA on rodent models and nonhuman primates to support the rationale for further development of this therapeutic strategy.

For the validation of any vaccine, significant questions regarding the most appropriate models, their species, age, 
immune status, dose, route of immunization, and potential interference from multiple vaccinations against different viruses need to be addressed. An essential question is the cost of the vaccine, because the disease is endemic in developing countries. Changes in trade, travel, and global climate have aided the spread of mosquito species worldwide. This may potentially cause public health threats by giving rise to more outbreaks in the future, causing substantial morbidity and loss of economic productivity. An effective vaccine is urgently needed.

\section{Conclusion}

The newly re-emerged CHIKV is actually an old virus, which was localized in the tropics but has now become a global disease. Unique issues are related to CHIKV infection, such as the mysterious behavior of dramatic outbreaks interspersed by periods of prolonged absence, changes in viral genome leading to changes in virus vector adaption, chronic and recurrent arthralgia, and socioeconomic impacts. Currently, there is no consensus as to how an individual is protected from CHIK. Several vaccine candidates have reached the stage of human clinical trials. The progress achieved so far suggests that the development of a safe and effective CHIK vaccine is within reach.

\section{Acknowledgment}

The authors thank Neena Grover and Gerald Miller for editing the English language and grammar of the manuscript.

\section{Disclosure}

The authors report no conflicts of interest in this work.

\section{References}

1. Simon F, Savini H, Parola P. Chikungunya: a paradigm of emergence and globalisation of vector borne diseases. Med Clin North Am. 2008;92: 1323-1343.

2. Sudeep AB, Parashar D. Chikungunya: an overview. J Biosci. 2008;33: 443-449.

3. Chevillon C, Braint L, Renaud F, Devaux C. The Chikungunya threat: an ecological and evolutionary perspective. Trends Microbiol. 2008;16: $80-88$.

4. Bodenmann P, Genton B. Chikungunya: an epidemic in real time. Lancet. 2006;368:258.

5. Benjamin M. Chikungunya is not a Swahii word; it is from the Makonde language! Available from: http://kamusiproject.org/en/node/144. Accessed March 6, 2013.

6. Muyembe TJ, Peyrefitte CN, Yogolelo R, et al. Epidemic of Chikungunya virus in 1999 and 2000 in the Democratic Republic of the Congo. Med Trop. 2003;63:637-638.

7. Ng LFP, Ojcius DM. Chikungunya fever-re-emergence of an old disease. Microbes Infect. 2009;11:1163-1164.

8. National Vector Borne Disease Control Programme. Directorate General of Health Services, Ministry of Health and family welfare, India. Chikungunya fever. Available from: http://www.nvbdcp.gov.in. Accessed March 6, 2013.
9. Patrick B, Blaise G. Chikungunya: an epidemic in real time. Lancet Infect Dis. 2006;368:258.

10. Rezza G, Nicoletti L, Angelini R, et al. Infection with chikungunya virus in Italy: an outbreak in a temperate region. Lancet. 2007;370: 1840-1846.

11. Grandadam M, Caro V, Plumet S, et al. Chikungunya virus, Southeastern France. Emerg Infect Dis. 2011;17:910-913.

12. Mari BR, Peydro JR. Current status and eco-epidemiology of mosquitoborne arboviruses in Spain. Rev Esp Salud Publica. 2010;84:255-269. Spanish.

13. Labadie $K$, Larcher T, Joubert $C$, et al. Chikungunya disease in nonhuman primates involves long-term viral persistence in macrophages. J Clin Invest. 2010;120:894-906.

14. Krishnamoorthy K, Harichandrakumar KT, Kumari AK, Das LK. Burden of Chikungunya in India: estimates of disability adjusted life years (DALY) lost in 2006 epidemic. J Vector Borne Dis. 2009;46: 26-35.

15. Karabatsos N. Antigenic relationship of group Arboviruses by plaque reduction neutralization testing. Am J Trop Med Hyg. 1975;24:527.

16. Higashi N, Matsumoto A, Tabata K, Nagatomo Y. Electron microscope study of development of Chikungunya virus in green monkey kidney stable (VERO) cells. Virology. 1967;33:55-69.

17. Powers AM, Brault AC, Shirako Y, et al. Evolutionary relationships and systematics of the alphaviruses. J Virol. 2001;75:10118-10131.

18. Simizu B, Yamamoto K, Hashimoto K, Ogata T. Structural proteins of chikungunya virus. J Virol. 1984;51:254-258.

19. Strauss JH, Strauss EG. The alphaviruses: gene expression, replication, and evolution. Microbiol Rev. 1994;58:491-562.

20. Khan AH, Morita K, Parquet MC, Hasebe F, Mathenge EG, Igarashi A. Complete nucleotide sequence of Chikungunya virus and evidence for an internal polyadenylation site. J Gen Virol. 2002;83:3075-3084.

21. Porterfield JH. Antigenic characteristic and classification of Togaviridae. In: Schlesinger RW, editor. The Togaviruses. New York, NY: Academic Press; 1980.

22. Van Regenmortel MHV, Fauquet CM, Bishop DHL, et al. Virus Taxonomy: Seventh Report of the International Committee on Taxonomy of Viruses. San Diego, CA: Academic Press; 2000.

23. Weaver SC, Frey TK, Huang HV, et al. Togaviridae. In: Fauquet CM, Mayo MA, Maniloff J, Desselberger U, Ball LA, editors. Virus Taxonomy: Eighth Report of the International Committee on Taxonomy of Viruses. Amsterdam, The Netherlands: Elsevier Academic Press; 2005.

24. Jeandal P, Josse R, Durand JP. Exotic viral arthritis: role of alphavirus. Med Trop. 2004;64:81-88.

25. Zeller HG. Dengue, arbovirus and migration in the Indian Ocean. Bull Soc Pathol Exot. 1998;91:56-60. French.

26. Lam SK, Chua KB, Hooi PS, et al. Chikungunya infection - an emerging disease in Malaysia. South East Asian J Trop Med Public Health. 2001;32:447-451.

27. Jupp PG, McIntosh BM. Aedes furcifer and other mosquitoes as vectors of chikungunya virus at Mica, northeastern Transvaal, South Africa. J Am Mosq Control Assoc. 1990;6:415-420.

28. Lahariya C, Pradhan SK. Emergence of chikungunya virus in Indian Subcontinent after 32 years: a review. J Vect Borne Dis. 2006;43: $151-160$.

29. Mohan A, Kiran DHN, Manohar IC, Kumar DP. Epidemiology, clinical manifestation and diagnosis of chikungunya fever: lesson learned from the reemerging epidemic. Indian J Dermatol. 2010;55:54-64.

30. Singh P, Mittal V, Rizvi MMA, et al. The first dominant co-circulation of both dengue and Chikungunya viruses during the post-monsoon period of 2010 in Delhi, India. Epidemiol Infect. 2012;140:1337-1342.

31. Chahar HS, Bharaj P, Dar L, Broor S. Co-infections with Chikungunya virus and dengue virus in Delhi, India. Emerg Infect Dis. 2009;15: 1077-1080.

32. Neogi DK, Bhattacharya N, Mukherjee KK, et al. Serosurvey of Chikungunya antibody in Calcutta metropolis. J Commun Dis. 1995;27: $19-22$. 
33. Thonnon J, Spiegel A, Diallo M, Diallo A, Fontenille D. Chikungunya virus outbreak in Senegal in 1996 and 1997. Bull Soc Pathol Exot. 1999;92:79-82. French.

34. Yergolkar PN, Tandale BV, Arankalle VA, et al. Chikungunya outbreaks caused by African genotype, India. Emerg Infect Dis. 2006;12: $1580-1583$.

35. Licia B, Silvia M, Marina S, et al. The re-emergence of an old disease: Chikungunya fever. In: Rodriguez-Morales, editor. Current Topics in Tropical Medicine. New York, NY: InTech; 2012.

36. Knudsen AB. Global distribution and continuing spread of Aedes albopictus. Parassitologia. 1995;37:91-97.

37. Diallo M, Thonnon J, Traore LM, Fontenille D. Vectors of Chikungunya virus in Senegal: current data and transmission cycles. Am J Trop Med Hyg. 1999;60:281-286.

38. McCrae AWR, Henderson BG, Kirya BG, Sempala SDK. Chikungunya virus in the Entebbe areas Uganda: isolations and epidemiology. Trans R Soc Trop Med Hyg. 1971;65:152-168.

39. Guilherme JM, Christine Gonella-Legall, Legalla F, Nakoume E, Vincent J. Seroprevalence of five arboviruses in zebu cattle in the central African Republic. Trans R Soc Trop Med Hyg. 1996;90:31-33.

40. Padbidri VS, Gnaneswar TT. Epidemiological investigations of chikungunya epidemic at Barsi, Maharashtra state, India. J Hyg Epidemiol Microbiol Immunol. 1979;23:445-451.

41. Robinson MC. An epidemic of virus disease in Southern Province, Tanganyika Territory, in 1952-1953. I Trans R Soc Trop Med Hyg. 1955;49:28-32.

42. Lumsden WH. An epidemic of virus disease in Southern Province, Tanganyika Territory, in 1952-1953. II. General description and epidemiology. Trans R Soc Trop Med Hyg. 1955;49:33-57.

43. Cavrini F, Gaibani P, Pierro AM, Rossini G, Landini MP, Sambri V. Chikungunya: an emerging and spreading arthropod borne viral disease. J Infect Dev Ctries. 2009;3:744-752.

44. Rao TR. Recent epidemics caused by chikungunya virus in India 1963-1965. Sci Cult. 1966;32:215-220.

45. Rao TR, Carey DE, Pavri KM. Preliminary isolation and identification of chikungunya virus from cases of dengue-like illness in Madras city. Indian J Med Res. 1965;53:689-693.

46. Shah KV, Gibbs CJ Jr, Banerjee G. Virological investigation of the epidemic of haemorrhagic fever in Calcutta: isolation of three strains of chikungunya virus. Indian J Med Res. 1964;52:676-693.

47. Thiruvengadam KV, Kalyanasundaram V, Rajgopal J. Clinical and pathological studies on Chikungunya fever in Madras City. Indian $J$ Med Res. 1965;53:729-744.

48. Jadhav M, Namboodripad M, Carman RH, Carey DE, Myers RM. Chikungunya disease in infants and children in Vellore: a report of clinical and haematological features of virologically proved cases. Indian J Med Res. 1965;53:764-776.

49. Rodrigues FM, Patankar MR, Banerjee K, et al. Etiology of the 1965 epidemic of febrile illness in Nagpur city, Maharashtra state, India. Bull World Health Organ. 1972;46:173-179.

50. Mourya DT. Absence of transovarial transmission of chikungunya virus in Ae. Aegypti and Ae. albopictus. Indian J Med Res. 1987;85:593-595.

51. Chhabra M, Mittal V, Bhattacharya D, Rana UVS, Lal S. Chikungunya fever: a reemerging viral infection. Indian J Med Microbiol. 2008;26: $5-12$.

52. Bessaud M, Peyrefitte CN, Pastorino BAM, et al. Chikungunya virus strains, Reunion Island outbreak. Emerg Infect Dis. 2006;12:1604-1606.

53. Schuffenecker I, Iteman I, Michault A, et al. Genome microevolution of chikungunya viruses causing the Indian Ocean outbreak. PLoS Med. 2006;3:e263.

54. Kowalzik S, Xuan NV, Weissbrich B, et al. Characterisation of a chikungunya virus from a German patient returning from Mauritius and development of a serological test. Med Microbiol Immunol. 2008;197: 381-386.

55. Kariuki Njenga M, Nderitu L, Ledermann JP, et al. Tracking epidemic Chikungunya virus into the Indian Ocean from East Africa. J Gen Virol. 2008;89:2754-2760.
56. Renault P, Solet JL, Sissoko D, et al. A major epidemic of chikungunya virus infection on Reunion Island, France, 2005-2006. Am J Trop Med Hyg. 2007;77:727-731.

57. Laras K, Sukri NC, Larasati RP, et al. Tracking the re-emergence of epidemic chikungunya virus in Indonesia. Trans R Soc Trop Med Hyg. 2005;99:128-141.

58. Yusof MP, Kuen LS, Adnan N, et al. Epidemiology and molecular characterization of chikungunya virus involved in the 2008 to 2009 outbreak in Malaysia. J Gen Mol Virol. 2011;3:35-42.

59. Theamboonlers A, Rianthavorn P, Praiantathavorn K, Wuttirattanakowit N, Poovorawan Y. Clinical and molecular characterization of chikungunya virus in South Thailand. Jpn J Infect Dis. 2009;62:303-305.

60. Hapuarachchi HC, Bandara KB, Sumanadasa SD, et al. Re-emergence of chikungunya virus in South-east Asia: virological evidence from Sri Lanka and Singapore. J Gen Virol. 2010;91(Pt 4):1067-1076.

61. Pfeffer M, Loscher T. Cases of chikungunya imported into Europe. Euro Surveill. 2006;11:e60316.2.

62. Ligon BL. Re-emergence of an unusual disease: the chikungunya epidemic. Semin Pediatr Infect Dis. 2006;17:99-104.

63. Centre for Disease Control. Chikungunya fever among US Peace Corps volunteers - Republic of the Philippines. MMWR Morb Mortal Wkly Rep. 1986;35:573-574.

64. Qiaoli Z, Jianfeng H, De W. Maiden outbreak of Chikungunya in Dongguan City, Guangdong Province, China: epidemiology characteristics. PloS One. 2012;7(8):e42830.

65. Sebastian MR, Lodha R, Kabra SK. Chikungunya infection in children. Indian J Pediatr. 2009;76:185-189.

66. Deller JJ Jr, Russell PK. An analysis of fevers of unknown origin in American soldiers in Vietnam. Ann Intern Med. 1967;66:1129-1143.

67. McGill PE. Viral infections: alpha-viral arthropathy. Baillieres Clin Rheumatol. 1995;9:145-150.

68. Adebajo AO. Rheumatic manifestations of tropical diseases. Curr Opin Rheumatol. 1996;8:85-89.

69. Chhabra M, Mittal V. Chikungunya fever. Tropical and emerging disease infection. In: Magill AJ, Hill DR, Solomon T, Ryan ET, editors. Tropical Medicine and Emerging Infectious Diseases. Philadelphia, PA: Elsevier; 2013.

70. Deller JJ Jr, Russell PK. Chikungunya disease. Am J Trop Med Hyg. 1968; 17:107-111.

71. Fourie ED, Morrison JG. Rheumatoid arthritic syndrome after chikungunya fever. S Afr Med J. 1979;56:130-132.

72. Brighton SW, Prozesky OW, de la Harpe AL. Chikungunya virus infection. A retrospective study of 107 cases. S Afr Med J. 1983;63:313-315.

73. Brighton SW, Simson IW. A destructive arthropathy following Chikungunya virus arthritis - a possible association. Clin Rheumatol. 1984;3:253-258.

74. Brighton SW. Chikungunya virus infections. SAfr Med J. 1981;59:552.

75. Pialoux G, Gauzere BA, Jaureguiberry S, Strobel M. Chikungunya an epidemic arbovirosis. Lancet Infect Dis. 2007;7:319-327.

76. Myers RM, Carey DE. Concurrent isolation from patient of two arboviruses, Chikungunya and dengue type 2. Science. 1967;157:1307-1308.

77. Vanlandingham DL, Hong C, Klingler K, et al. Differential infectivities of o'nyongnyong and chikungunya virus isolates in Anopheles gambiae and Aedes aegypti mosquitoes. Am J Trop Med Hyg. 2005;72: 616-621.

78. Saxena SK. Re-emergence of the knotty chikungunya virus: facts, fear or fiction. Future Virol. 2007;2:121-126.

79. Staples JE, Breiman RF, Powers AM. Chikungunya fever: an epidemiological review of a reemerging infectious disease. Clin Infect Dis. 2009;49:942-948.

80. Panning M, Hess M, Fischer W, Grywna K, Pfeffer M, Drosten C. Performance of the real star Chikungunya virus real-time reverse transcription-PCR kit. J Clin Microbiol. 2009;47:3014-3016.

81. Joseph AY, Babu VS, Dev SS, et al. Rapid detection and characterization of chikungunya virus by RT-PCR in febrile patients from Kerala, India. Indian J Exp Biol. 2006;46:573-578. 
82. Parida MM, Santhosh SR, Dash PK, et al. Rapid and real-time detection of chikungunya virus by reverse transcription loop-mediated isothermal amplification assay. J Clin Microbiol. 2007;45:351-357.

83. Ng LF, Chow A, Sun YJ, et al. IL-1beta, IL-6, and RANTES as biomarkers of Chikungunya severity. PLoS One. 2009;4:e4261.

84. Couderc T, Chrétien F, Schilte C, et al. A mouse model for Chikungunya: young age and inefficient type-I interferon signaling are risk factors for severe disease. PloS Path. 2008;e29.

85. Chow A, Her Z, Ong EKS, et al. Persistent arthralgia induced by chikungunya virus infection is associated with interleukin-6 and granulocyte macrophage colony stimulating factor. J Infect Dis. 2011;203: 149-157.

86. Powers AM, Brault AC, Tesh RB, Weaver SC. Re-emergence of Chikungunya and O'nyong-nyong viruses: evidence for distinct geographical lineages and distant evolutionary relationships. J Gen Virol. 2000;81:471-479.

87. Pastorino B, Muyembe-Tamfum JJ, Bessaud M, Tock H, Durand JP, Peyrefitte $\mathrm{CN}$. Epidemic resurgence of chikungunya virus in Democratic Republic of the Congo: identification of a new central African strain. J Med Virol. 2004;74:277-282.

88. Tsetsarkin KA, Vanlandingham DL, McGee CE, Higgs S. A single mutation in chikungunya virus affects vector specificity and epidemic potential. PloS Path. 2007;3:e201.

89. Vazeille M, Moutailler S, Coudrier D, et al. Two chikungunya isolates from the outbreak of La Reunion (Indian Ocean) exhibit different patterns of infection in the mosquito, Aedes albopictus. Plos One. 2007;2:1-9.

90. Singh P, Mittal V, Rizvi MA, et al. Northward movement of East Central South African Genotype of Chikungunya virus causing an epidemic between 2006-2010 in India. J Infect Dev Ctries. 2012;6: 563-571.

91. Arankalle VA, Shrivastava S, Cherian S, et al. Genetic divergence of chikungunya viruses in India (1963-2006) with special reference to the 2005-2006 explosive epidemic. J Gen Virol. 2007;88:1967-1976.

92. Nareshkumar CVM, SaiGopal DVR. Re-emergence of chikungunya virus in Indian subcontinent. Indian J Virol. 2010;21:8-17.

93. Kumar NP, Joseph R, Kamaraj T, Jambulingam P. A226V mutation in virus during the 2007 chikungunya outbreak in Kerala, India. J Gen Virol. 2008;89:1945-1948.

94. Santhosh SR, Dash PK, Parida MM, Khan M, Tiwari M, Rao PVL. Comparative full genome analysis revealed E1:A226V shift in 2007 Indian chikungunya virus isolates. Virus Res. 2008;135:36-41.

95. Santhosh SR, Dash PK, Parida MM, Khan M, Rao PVL. Appearance of E1: A226V mutant Chikungunya virus in Coastal Karnataka, India during 2008 outbreak. Virol J. 2009;6:e172.

96. Das B, Sahu A, Das M, et al. Molecular investigations of chikungunya virus during outbreaks in Orrisa, Eastern India in 2010. Infect Genet Evol. 2012;12:1094-1101.

97. Sumathy K, Ella KM. Genetic diversity of chikungunya virus, India, 2006-2010, evolutionary dynamics and serotype analysis. J Med Virol. 2012;84:462-470.

98. Shrinet J, Jain S, Sharma A, et al. Genetic characterization of chikungunya virus from New Delhi reveal emergence of a new molecular signature in Indian isolates. Virol J. 2012;9:e100.

99. Rianthavorn P, Prianantathavorn K, Wuttirattanakowit N, Theamboonlers A. Poovorawan An outbreak of chikungunya in Southern Thailand from 2008 to 2009 caused by African strains with A226V mutation. Int J Infect Dis. 2010;145:e161-e165.

100. Ho K, Ang LW, Tan BH, et al. Epidemiology and control of chikungunya fever in Singapore. J Infect. 2011;62:263-270.

101. Jain M, Rai S, Chakravarti A. Chikungunya: a review. Trop Doc. 2008;38:70-72.

102. Brighton SW. Chloroquine phosphate treatment of chronic chikungunya arthritis. S Afr Med J. 1984;66:217-218.

103. De Lamballerie X, Boisson V, Reynier JC, et al. On chikungunya acute infection and chloroquine treatment. Vector Borne Zoonotic Dis. 2008;8:837-839.

104. Khan M, Santhosh SR, Tiwari M, Rao PVL, Parida M. Assessment of invitro prophylactic and therapeutic efficacy of chloroquine against chikungunya virus in Vero cells. J Med Virol. 2010;82:817-824.
105. Ravichandran R, Manian M. Ribavirin therapy for chikungunya arthritis. J Infect Dev Ctries. 2008;2:140-142.

106. Briolant S, Garin D, Scaramozzino N, Jouan A, Crance JM. In vitro inhibition of chikungunya and Semliki Forest viruses replication by antiviral compounds: synergistic effect of interferon-alpha and ribavirin combination. Antiviral Res. 2004;61:111-117.

107. Reiter P, Fontenille D, Paupy C. Aedes albopictus as an epidemic vector of chikungunya virus: another emerging problem? Lancet Infect Dis. 2006;6:463-464.

108. Cui F, Raymond M, Qiao CL. Insecticide resistance in vector mosquitoes in China. Pest Manag Sci. 2006;62:1013-1022.

109. Jaffar-Bandjee MC, Ramful D, Gauere BA, et al. Emergence and clinical insights into the pathology of Chikungunya infection. Expert Rev Anti Infect Ther. 2010;8:897-996.

110. Ng LC, Hapuarachchi HC. Tracing the path of chikungunya virusevolution and adaption. Infect Genet Evol. 2010;10:876-885.

111. Harrison VR, Eckels KH, Bartelloni PJ, Hampton C. Production and evaluation of a. a formalin-killed Chikungunya vaccine. J Immunol. 1971;107:643-647.

112. Eckels KH, Harrison VR, Hetrick FM. Chikungunya virus vaccine prepared by a. Tween-ether extraction. Appl Microbiol. 1970;19:321-325.

113. Tiwari M, Parida M, Santhosh SR, Khan M, Dash PK, Rao PV. Assessment of immunogenic potential of Vero adapted formalin inactivated vaccine derived from novel ECSA genotype of Chikungunya virus. Vaccine. 2009;27:2513-2522.

114. Levitt NH, Ramsburg HH, Hasty SE, Repik PM, Cole FE Jr, Lupton HW. Development of an attenuated strain of chikungunya virus for use in vaccine production. Vaccine. 1986;4:157-162.

115. Turell MJ, Malinoski FJ. Limited potential for mosquito transmission of a live, attenuated chikungunya virus vaccine. Am J Trop Med Hyg. 1992;47:98-103.

116. Edelman R, Tacket CO, Wasserman SS, Bodison SA, Perry JG, Mangiafico JA. Phase II safety and immunogenicity study of live chikungunya virus vaccine TSI-GSD-218. Am JTrop Med Hyg. 2000;62:681-685.

117. Wang E, Volkova E, Adams AP, et al. Chimeric alphavirus vaccine candidates for chikungunya. Vaccine. 2008;26:5030-5039.

118. Kenney JL, Volk SM, Pandya J, et al. Stability of RNA virus attenuation approaches. Vaccine. 2011;29:2230-2234.

119. Pedersen CE, Robinson DM, Cole FE. Isolation of the vaccine strain of Venezuelan equine encephalomyelitis virus from mosquitoes in Louisiana. Am J Epidemiol. 1972;95:490-496.

120. Wang E, Kim DY, Weaver SC, Frolov I. Chimeric chikungunya viruses are nonpathogenic in highly sensitive mouse models but efficiently induce a protective immune response. J Virol. 2011;85:9249-9252.

121. Plante K, Wang E, Partidos CS, et al. Novel chikungunya vaccine candidate with an IRES-based attenuation and host range alteration mechanism. PLoS Pathog. 2011;7:e1002142.

122. Muthumani K, Lankaraman KM, Laddy DJ, et al. Immunogenicity of novel consensus-based DNA vaccines against Chikungunya virus. Vaccine. 2008;26:5128-5134.

123. Mallilankaraman $\mathrm{K}$, Shedlock DJ, Bao H, et al. A DNA vaccine against chikungunya virus is protective in mice and induces neutralizing antibodies in mice and nonhuman primates. PLoS Negl Trop Dis. 2011;5:e928.

124. Akahata W, Yang ZY, Andersen $H$, et al. A virus like particle vaccine for epidemic chikungunya virus protects nonhuman primates against infection. Nat Med. 2010;16:334-338.

125. ClinicalTrials.gov. VRC 311: a Phase 1 open label, dose-escalation clinical trial to evaluate the safety and immunogenicity of a virus-like particle (VLP) Chikungunya vaccine, VRC-CHKVLP059-000-VP, in healthy adults. Available from: http://clinicaltrials.gov/ct2/show/ NCT01489358. Accessed March 6, 2013.

126. Couderc T, Khandoudi N, Grandadam M, et al. Prophylaxis and therapy for Chikungunya virus infection. J Infect Dis. 2009;200: 516-523.

127. Dash PK, Tiwari M, Santhosh SR, Parida M, Rao PVL. RNA interference mediated inhibition of Chikungunya virus replication in mammalian cells. Biochem Biophys Res Commun. 2008;376:718-722. 
Vaccine: Development and Therapy

Dovepress

\section{Publish your work in this journal}

Vaccine: Development and Therapy is an international, peer-reviewed, open access journal that spans the spectrum of vaccine design and development through to clinical applications. The journal is characterized by the rapid reporting of application notes, reviews, original research and clinical studies in all therapeutic areas. Clinical outcomes, patient safety,

and programs for the development and effective, safe, and sustained use of vaccines will be a feature of the journal. The manuscript management system is completely online and includes a very quick and fair peer-review system. Visit http://www.dovepress.com/testimonials.php to read real quotes from published authors.

Submit your manuscript here: http://www.dovepress.com/vaccine-development-and-therapy-journal 